\begin{tabular}{|c|c|c|}
\hline $\begin{array}{l}\text { SUCRS } \\
\text { PUCR }\end{array}$ & $\begin{array}{l}\text { ESCOLA DE } \\
\text { HUMANIDADES }\end{array}$ & $\begin{array}{l}\text { Revista de Filosofia da PUCRS } \\
\text { Veritas, Porto Alegre, v. } 65 \text {, n. 1, p. 1-14, jan.-mar. } 2020 \\
\text { e-ISSN: } 1984-6746 \text { | ISSN-L: 0042-3955 }\end{array}$ \\
\hline do $h t t p: / / d x$ & $\mathrm{org} / 10.15448 / 1984-6746.2020 .1 .36681$ & \\
\hline
\end{tabular}

SEÇÃO: MORAL \& POLITICAL PHILOSOPHY

\title{
Opinião provável sobre guerra e paz no Indiarum lure, de Juán Solórzano Pereira
}

\author{
Probable opinion about war and peace in Indiarum iure by Juan Solorzano Pereira \\ Opinión probable sobre guerra y paz en el Indiarum iure de Juán Solórzano Pereira
}

Gonzalo Tinajeros Arce ${ }^{1}$ orcid.org/0000-0003-4510-4906 gonzalo.tinajeros@gmail.com

Recebido em: 19 dez. 2019 Aprovado em: 20 jan. 2020 Publicado em: 12 mai. 2020.
Resumo: O presente artigo é um estudo de escolástica barroca colonial que combina elementos lógicos, raciocínios práticos e probabilismo, para compreender o movimento processual das deliberações jurídico-políticas sobre "guerra e paz" no pensamento de Juan de Solorzano Pereira (1575-1655). Pensador escolástico do período barroco ibero-americano que residiu por mais de duas décadas nas Índias ocidentais (Vice-reinado do Perú e na Audiência de Charcas, hoje Bolívia). que elaborou e sistematizou o Direito Indiano, De Indiarum iure. Corpo sistemático e erudito no qual se encontram compiladas cédulas reais, leis, disposições ou mandatos régios; os quais eram destinados a guiar os assuntos próprios de governo nas Índias ocidentais, fundamentados na guerra justa e na paz republicana. $\mathrm{Na}$ Filosofia do Direito Indiano de Solórzano Pereira, a opinião provável sobre fatos e direitos não se restringe aos atos perfeitos e os absolutos que se acreditam ter em opiniões mais prováveis do passado e do presente, porque a probabilidade nessa filosofia do direito está aberta ao futuro condicional, onde novas opiniões podem produzir dúvidas nos fatos e no direito, podendo se tornar em opiniões mais coerentes, seguras e mais prováveis que as anteriores, pela aceitabilidade racional sobre o direito em questão. Erros abrem brechas e podem ser motivos suficientes para modificar direitos por usucapião, retenção, prescrição, restituição. Palavras-chaves: Opinião provável. Guerra. Paz. Escolástica barroca colonial. Solórzano Pereira

Abstract: This article is a study of the colonial baroque scholastic that combines logic elements, practical reasoning and probabilism for understanding the processual movements regarding juridical and political deliberations of "war and peace" into the thoughts of Juan de Solórzano Pereira (1575-1655). Scholastic thinker of the Ibero-American baroque period, Solórzano Pereira lived for two decades in the Spanish West Indies (Peru and Bolivia), where he elaborated and systematized the Indian Law, De Indiarum Iure. Systematic and erudite political-legal body that compiled laws as well as royal prerogatives and warrants. They were destinated to beacon government issues in the Spanish West Indies, grounded in righteous war and republican peace. In the philosophy of Indian Right by Solórzano Pereira, probable opinion about facts and right are not to be restricted to absolute and perfect acts credited to opinions more probable in the past and the present than probability opinions open to a conditional future, when new opinions may rise doubts between facts and rights becoming themselves more coherent, safer and more probable than previous ones, due to rational acceptance towards the present right. Mistakes create contingencies and are reason enough to modify rights for usucapion, retention, prescription, and restitution.

Keywords: Probable opinion. War. Peace. Colonial Scholastic Baroque. Solórzano Pereira.

Resumen: El presente artículo es un estudio de escolática barroca colonial que combina elementos lógicos, raciocínios prácticos y probabilismo, para comprender el movimiento procesual de las deliberaciones juridico-políticas sobre "guerra y paz" en el pensamiento de Juan de Solórzano Pereira (1575-1655). Pensador escolástico del periódo barroco lberoamericano que vivió por más de dos décadas en las Indias occidentales (Virreinato del Perú y la Audiencia de Charcas, hoy
Artigo está licenciado sob forma de uma licença Creative Commons Atribuição 4.0 Internacional. 
Bolivia) que elaboró y sistematizó el Derecho Indiano, De Indiarum iure. Cuerpo sistemático y erudito en el cual se encontraban compiladas cédulas reales, leis, disposiciones o mandatos regios; los cuales estaban destinados a guiar los asuntos propios del gobierno en las Indias occidentales, fundamentados en los principios de la guerra justa y la paz republicana. En la filosofia del Derecho Indiano de Solórzano Pereira, la opinión probable sobre hechos y derecho no se restringe a los actos perfectos y absolutos con creencias seguras en opiniones más probables del pasado y del presente, porque la probabilidad en esta filosofia del derecho está abierta al futuro condicional, donde nuevas opiniones pueden producir dudas en los hechos y el derecho, pudiendo tornarse en opiniones más coherentes, seguras y más probables que las anteriores por la aceptabilidad racional sobre el derecho en cuestion. Errores abren brechas y pueden ser motivos suficientes para modificar derechos por usucapión. retención, prescripción, restitución.

Palabras claves: Opinión probable. Guerra. Paz. Escolástica Barroca Colonial. J. Solórzano Pereira.

\section{Introdução: Configuração da opinião mais provável sobre guerra e senhorio espanhol no Novo Mundo}

Para realizar este estudo filosófico. apresentarei e discutirei as ideias políticojuridicas mais prováveis sobre guerra e paz, de Juan de Solórzano Pereira. Pensador que agiu efetivamente na primeira metade do século XVII nas Índias Ocidentais (Vice-reino de Perú e Audiência de Charcas), produzindo distintas fundamentações jurídico-políticas no intuito de legitimar e legalizar as atividades do reino da Espanha no novo mundo com a declaração de guerra justa "iustum bellum" e a posterior retenção jurídica dos antigos reinos absolutistas e tirânicos² dos caciques indígenas. Visando que os principios naturais e civis do direito das gentes passassem a vigorar politicamente para os povos do mundo recém descoberto, e no âmbito espiritual em que a pregação livre da religião cristã-católica fosse possivel com tolerância, em territórios governados por senhores infiéis.

Solórzano Pereira elaborou distintos argumentos filosóficos, políticos, juridicos e religiosos para delinear de maneira erudita, aquilo que seria a guerra justa e as suas situações prováveis de legitimidade e de legalidade, levando a termo suas fundamentações, para nos fazer compreender, racionalmente, quando e por que se tornaria relevante para um Estado intervir militarmente em um conflito armado, o qual não apresenta nenhuma forma possivel de resolução pacífica. Afinal, é através de uma guerra justa que se pode retomar, mais tarde, a uma nova situação viável de paz entre Estados.

Juan Solórzano Pereira analisa no Indiarum lure possiveis situações conflitivas que gerassem licitude e legalidade da guerra justa para entidades políticas cristãs. Ele, assim, entende que pode haver uma declaração de guerra justa ${ }^{3}$ dos espanhóis aos indígenas do Novo Mundo, os quais, alegadamente, injuriaram, em ocasiões diversas, os princípios e os valores religiosos, humanos e políticos civilizados, assentados no direito divino, no direito natural e no ius gentium. ${ }^{4}$ Como é sabido, esses direitos regiam a vida das nações europeias desde a antiguidade; a autoridade do império romano governado pelos imperadores Constantino e Justiniano, organizou,

\footnotetext{
"[...] para justificar la ocupación de las Indias por España incluye Solórzano la tiranía que padecian los indios antes de la venida de los españoles. Este nuevo aspecto es el que estudia Vitoria en el quinto título de los que él considera legítimos y que formula de la siguiente manera: 'Otro título podría ser la tiranía de los mismos caciques de los indios o sus leyes tiránicas en daño de los inocentes; el sacrificio, por ejemplo, de hombres inocentes o la matanza, otras veces, de hombres libres de culpa, con el fin de comer su carne'. Son los diversos matices en que se manifiesta la tiranía de los caciques en daño de los inocentes, es decir, con lesión de unos derechos que les correspondian como a criaturas racionales, imágenes de Dios. Interviene, pues, un elemento nuevo y determinante: la injuria inferida, que rebasa la mera consideración de pecado contra la naturaleza y exige una consideración aparte y autónoma". BACIERO, Carlos. Fundamentación filosófica de la defensa de la corona ante Europa. SOLORZANO PEREIRA, J. De Indiarum lure (Liber III: De retentione Indiarum): Estudios preliminares. Madrid: CSIC (Colección Corpus Hispanorum de PACE), 1994. p. 79-80.

3 Para um estudo pormenorizado sobre o tratamento conceitual de querra justa "iustum bellum" em J. Solórzano Pereira, veja-se: TINAJEROS, Gonzalo. Um estudo filosófico comparado sobre o conceito de Guerra Justa em F. Vitoria, J. Solórzano Pereira e G.W.F. Hegel. Revista Clássica Boliviana, La Paz n. IX, p. 121-152, 2018. Disponivel em: http://www.estudiosclasicosbolivia.org/IMG/pdf/classica_ix_colores.pdf. Acesso em: 18 dez. 2019.

4 "El ius gentium al estar fundado de manera principal en el derecho natural y en ocasiones en el consenso humano, legitima el uso de la fuerza hacia aquella nación que viole las instituciones del ius gentium con el fin de que vuelvan a ser restablecidas. El uso legitimo de la fuerza es la guerra justa: una institución de derecho natural fundado en el derecho natural a la conservación que poseen los seres humanos como individuos y como ciudadanos. Entramos a la teoria Vitoriana de la guerra justa. Conviene puntualizar que, ayer como hoy, siendo la guerra un instrumento legítimo de los Estados para la restitución de la 'paz y la seguridad' enajenada por las acciones de otro Estado, para Francisco de Vitoria es un recurso de 'necesidad extrema' y del que solo cabe hacer uso una vez que se han agotado todas las vías de resolución pacífica". PONCELA GONZÁLEZ, Ángel. Filosofía del Derecho en sentido pragmático: Francisco de Vitoria y la escuela de Salamanca. In: CULLETON, A.; HOFMEISTER PICH, R. (edited). Right and Nature and the First and Second Scholasticism. Belgium: Brepol 2014 . p. 147.
} 
juridicamente, a vida dos povos europeus segundo as regras do direito civil e do direito das gentes.

O "encontro" dos espanhóis com os indigenas do Novo Mundo, de certo modo, foi mais um desencontro do que um "encontro" de valores civilizatórios, uma vez que o ius gentium, por exemplo, sendo o direito que deveria ter regido as relações dos europeus com os indígenas, era absolutamente desconhecido ou não reconhecido pelos indigenas; afinal, poder-seia alegar que, esses últimos, desde o início, não permitiram o estabelecimento lícito de representação de embaixadores, sacrificando 5 os primeiros representantes políticos, espanhóis e portugueses ${ }^{6}$, com a prática ritual da antropofagia. Semelhantemente, o comércio internacional com os indígenas não foi viável, fossem esses índios do caribe, chiriguanos, ${ }^{7}$ chichimecas, $^{8}$ incas, maias, chilenos ${ }^{9}$ etc., uma vez que não foi possivel desenvolver, nos primeiros periodos, aquela forma preventiva e eficaz de conter um conflito (armado) entre povos distintos. Com efeito, mostrou-se impossivel a pregação livre da fé cristã ${ }^{10}$ desnudando o fato de que os diversos povos indígenas não tinham desenvolvido dentro das suas civilizações os valores da tolerância religiosa. Em muitas ocasiões, ganhou-se conhecimento de que foram sacrificados os missionários ou os pregadores cristãos, devido à selvageria e brutalidade dos seus captores.

Por esses motivos, Solórzano Pereira seguiu às tradições filosófico-juridicas e religioso-cristãs, para intentar averiguar o valor real do justo título: Domínio Imperial das Índias Ocidentais; isso mediante usos racionais de opiniões prováveis perante dúvidas de se houve ou não houve A prática religiosa e militar dos sacrificios humanos era um costume generalizado entre vários povos indigenas das Américas Central e
da América do Sul. José de ACOSTA no seu famoso livro: Historia natural y moral de las İndias en que se tratan las cosas notables del cielo y
elementos, metales, plantas, y animales dellas y los ritos, y ceremonias, leyes y govierno, y guerras de los indios (Capitulos XIX, XX e XXI), Impresso
em Sevilla, Juan de Leon 1590, p. 348-356. Versão disponivel em: http://Www.memoriachilena.cl/602/w3-article-8652.html, e, http://www.
iberoamericadigital.net/BDPI/. Acesso em: 18 dez. 2019. Explicita os detalhes ritualísticos dos distintos tipos de sacrificos humanos realizados
no Peru e no México, no periodo pré-colombiano. Os rituais em questão incluiam sacrifícios de crianças, de cativos de guerra, de estrangeiros
considerados hostis etc., tanto em tempos de guerras quanto em tempos de festividades religiosas e civis, tais como o "Racaxipe" e o "Valiztli".
6 "Ahi también están los ejemplos de los portugueses, que por las mismas causas incorporaron a su Imperio numerosas posesiones
de los indios occidentales adquiridas por este tipo de guerra (iusti belli imperio), como afirman Navarro, Molina (De iustitia et iure tract. II,
disp. 104, vers. Sexto) y muy recientemente Serafin Freitas que cita en el mismo sentido las elegantísimas palabras de Gerónimo Osorio".
SOLORZANO PEREIRA, J. De Indiarum iure (Liber III: De Retentione Indiarum - Caput IV). Madrid: Editora CSIC (Colección Corpus His-
panorum de PACE), 1994, p. 325 .
7 "Los abusos y delitos de los no cristianos son la causa de que queden sometidos a nuestra jurisdicción, incluso si son extranjeros, como se dice en una ley canónica: Tiene a veces poder incluso contra extranjeros, si hubieren cometido algún desafuero. [...] Con base en estas razones concluye Juan de Matienzo (In: tractatu manuscripto De moderamine Regni Peruani lib. II, cap.9) que se puede declarar justamente la guerra a los indios chiriguanos por habernos faltado muchas veces a la palabra dada y por amedrentar com sus amenazas y crueldades a otros pueblos de indios que recibieron el evangelio o podrian recibirlo fácilmente; y por comerse con increible voracidad y salvajismo a la mayor parte de los prisioneros". SOLÓRZANO PEREIRA, J. De Indiarum iure (Liber III: De Retentione Indiarum - Caput IV). Madrid: Editora CSIC (Colección Corpus Hispanorum de PACE), 1994, p. 323-325 (grifo do autor).

8 "Antonio de Herrera nos dejó escrito en numerosos lugares de su Historia general de las Indias que la misma decisión se tomó muchas veces en el Consejo Supremo de Indias sobre los Chichimecas de Nueva España y sobre los caribes y canibales de tierra Firme e islas adyacentes, ordenando que se hiciesen esclavos de quienes los capturaban". SOLORZANO PEREIRA, J. De Indiarum iure (Liber III: De Retentione Indiarum - Caput IV). Madrid: Editora CSIC (Colección Corpus Hispanorum de PACE), 1994, p. 325.

9 Sobre a extrema ferocidade e desumana crueldade dos índios Chilenos, Solórzano Pereira escreve no Livro III. De Retentione Indiarum - Caput IV: "Pero no sólo no abrazan la fe, sino al contrario aniquilan y perturban, con incursiones e invasiones a diario, tanto a nuestros compatriotas como sobre todo a otros indios convertidos y amigos, y han destruido algunas ciudades y fortalezas bien fortificadas de los españoles, y dieron muerte a traición a aquel insigne varón, Martín García de Loyola, Caballero de la Orden de Calatrava, Gobernador de dicho Reino. Teniendo en cuenta esta situación nuestro Piadosísimo Rey Felipe III mandó expedir una cédula, dada en Ventosilla a 26 de mayo de 1608 en la que ordenó que se declare guerra abierta a los dichos indios y que los prisioneros mayores de diez años fueran reducidos a la esclavitud. [...] Sin embargo, ya dentro de las provincias rebeldes de los Chilenos, no pudieron conseguir de ellos ni en cuatro, pero ni siquiera en diez años, cosa que se pareciera a justicia y rectitud moral. Asesinados algunos de ellos por los bárbaros, se volvieron dejando la obra sin terminar, incluso en peor situación. Creció, en efecto, la ferocidad e insolencia de los indios al interpretar como miedo nuestra blandura, y al comprobar que ya no se les hostigaba asiduamente con guerras, como antes, cuando erán más numerosos y que estaban más preparados para la guerra y para ocasionarnos otros daños. Informado de nuevo de estos hechos nuestro Rey y Señor Felipe IV (que actualmente piadosa y felizmente reina, y ojalá siga reinando aún com más piedad y felicidad por muchos años) mandó expedir otra cédula muy recientemente, a 13 de abril de 1625. En ella ordena y prescribe al excelentísimo Virrey de su Reino del Perú, Marqués de Guadalcázar, que, si le pareciera oportuno hacerlo, declare la guerra a los indios Chilenos por todos los medios posibles, llámese guerra defensiva, ofensiva o vengativa, y se haga a los prisioneros esclavos de los que los capturan". SOLÓRZANO PEREIRA, J. De Indiarum iure (Liber III: De Retentione Indiarum - Caput IV). Madrid: Editora CSIC (Colección Corpus Hispanorum de PACE), 1994. P. 325-327.

10 "Los cristianos tienen derecho de predicar y de anunciar el Evangelio en las provincias de los bárbaros [...] Porque si tienen derecho de peregrinar por aquellos lugares y comerciar com sus gentes, pueden también enseñar la verdad a los que quieran oir; mucho más tratándose de lo concerniente a la salvación y felicidad que de lo que atañe a cualquier otra humana disciplina [...] porque son prójimos, como se há dicho arriba; pero a cada uno confió Dios el cuidado de su prójimo; luego toca a los cristianos instruir em las cosas divinas a aquellos que las ignoran". De VITORIA, F. Relección Primera -De los Indios recién descubiertos, Tercera Parte acápite 9. México: Editorial Porrúa, 2007, p.64-65, grifo nosso. 
alguma situação de guerra justa ${ }^{11}$ dos espanhóis contra os denominados bárbaros do Novo Mundo:

Es más, concedamos que en la dicha conquista del Nuevo Mundo se hubieran presentado algunas dudas que necesitaban clarificación y que los doctores consultados hubieran tenido opiniones diversas. Sin embargo, por el hecho mismo de haber expuesto varios de ellos como más verdadera y más probable (ut veriorem et probabiliorem proposuerunt) la opinión que favorecia la conquista, pudieron seguirla nuestros Reyes justa y lícitamente (iuste et legitime), aún cuando se trataba de invadir territorios ajenos. Tal es la opinión generalizada de todos los doctores que antes hemos citado, principalmente Vitoria, Cayetano y Silvestre Prierias, Azpilcueta, Valencia, Bañez, Baltasar de Ayala, Lorca, Suarez, Molina y otros muchos [...] Dejemos de lado, por lo demás, la opinión de otros autores que en este y en otros puntos estiman que van seguros quienes abrazan opiniones sólo probables, aunque haya otras más seguras y más probables (qui opiniones dumtaxat probabiles amplexantur, etiamsi aliae tutiores et probabiliores existant), sobre todo cuando se trata no ya de una duda de hecho, sino de derecho y de su interpretación y comprensión. ${ }^{12}$

Solórzano Pereira estuda as disputações filosóficas sobre a guerra justa, avaliando em cada momento o peso da argumentação filosófica, a intensidade da sua probabilidade de ser efetiva enquanto mais verdadeira e próxima aos fatos, igualmente tendo ela a capacidade compreensiva e interpretativa para clarificar e resolver as dúvidas de direito.

A opinião mais provável se aproxima racionalmente daquilo que pode ser a verdade na realidade, na medida em que esta opinião argumenta claramente desvelando os problemas contidos nas dúvidas de fato e de direito, apresentadas nas outras opiniões prováveis. Porém, a opinião mais provável expressa a forma mais segura possivel para resolver os conflitos "interpretativos e compreensivos" da verdade daquele assunto na realidade.

Na visão de Solórzano Pereira, a opinião mais provável tem o sustento material do ato perfeito presente no império da lei, e tem o sustento formal expresso nos fundamentos e princípios do direito natural, direito civil e do direito das gentes. A opinião mais provável tem validade no ato presente da realidade reconhecido nos principios próprios do direito (ex., boa-fé, aquisição, usucapião, retenção, prescrição, restituição etc.):

Efectivamente los actos perfectos y absolutos no quedan viciados por un impedimento sobrevenido. [...] El que haya podido haber algunos que en tiempos pasados o modernos hayan planteado dudas sobre esta conquista de las Indias, no contradice a la exposición anterior. Nuestros Reyes guiados por las consultas arriba indicadas, siempre tuvieron buena fe. Y ésta es la única que hay que tener en cuenta. porque en lo tocante a la buena fe y a la voluntad de obrar ha de prevalecer el juicio próprio, no el ajeno; y más se trata de una cuestión de hecho que de derecho. [...] Una creencia, con visos de probabilidad, adquiere fuerza de título (Et credulitas probabilis habet vim tituli), como enseñan notablemente Aretino, Alejandro de Imola y Mandeli; sobre todo tratándose de una prescripción (ubi in praescriptione) de treinta o cuarenta años [...] En una prescripción de este tipo cualquier título, incluso aparente e ilegitimo, es suficiente y hace buena fe, aunque después pueda invalidarse o se diga que un error injusto fue la causa de su deslizamiento [...] Es más, si el título tiene visos de probabilidad y es aceptable, aunque generado por un error de derecho o incluso de hecho dudoso (si titulus probabilis et tolerabilis sit et per errorem iuris aut etiam facti dubii conflatus), podrá ser suficiente en cualquier prescripción, incluso la que es ordinaria y la que requiere título. como prueban en general todos los comentaristas jurídicos. ${ }^{13}$

Na Filosofia do Direito Indiano de Solórzano Pereira, a opinião provável não necessariamente se restringe aos atos perfeitos e absolutos que

11 No tocante à guerra justa, SUÁREZ, Francisco (mestre influente de Juan Solórzano Pereira em Salamanca), em: De legibus- IV- De iure gentium. Madrid: C.S.I.C., 1973. Parte II - 19, p. 134 (linhas 10-13), escreve suas reflexões dentro de uma linha estritamente juridicista sobre a legalidade do direito de guerra e as sanções e reparações que se exigem do Estado infrator no ius gentium: "Lo mismo pienso del derecho de guerra. Parece pertenecer propiamente al derecho de gentes en cuanto se basa en el poder que tiene el Estado o la monarquía para imponer castigos o sanciones y exigir reparaciones por injurias que le ha inferido otro Estado".

12 SOLÓRZANO PEREIRA, J. De Indiarum iure (Liber III: De Retentione Indiarum -Caput II). Madrid: Editora CSIC (Colección Corpus Hispanorum de PACE), 1994, p. 267, grifo nosso.

13 SOLÓRZANO PEREIRA, J. De Indiarum iure (Liber III: De Retentione Indiarum -Caput II). Madrid: Editora CSIC (Colección Corpus Hispanorum de PACE), 1994, p. 275-277. 
se acreditam ter em opiniões mais prováveis do passado e do presente, porque a probabilidade nessa filosofia está aberta ao futuro condicional, onde novas opiniões podem produzir dúvidas nos fatos e no direito, podendo-se tornar em opiniões mais coerentes, seguras e mais prováveis que as anteriores, pela aceitabilidade racional sobre o direito em questão. Erros abrem brechas e podem ser motivos suficientes para modificar direitos por usucapião, retenção, prescrição, restituição ${ }^{14}$ etc. o que permanece é a boa-fé do sujeito manifesto na sua vontade de obrar, no seu próprio juízo e nos fatos produzidos pelos seu agir. Nesse último sentido, Solórzano faz referência à boa-fé dos monarcas espanhóis, que depois de escutar longas deliberações dos seus conselheiros mais iminentes, ${ }^{15}$ decidiram eles mesmos descobrir, conquistar e reter as Índias Ocidentais mediante uma guerra justa, dita legítima, e racional:

[...] nos tamen, qui illud tantum iustum et legitimum iudicamus quod iure, legibus et ratione ex omni sui parte subsistit, nullatenus volumus huius Novi Orbis imperium ob solam acquisitionem bellicam, de qua ultimo loco tractavimus, regibus nostris asserere, nisi prius eadem bella iuste, legitime indis inferri potuisse probaverimus. ${ }^{16}$

Para Solórzano, o título de domínio das Índias Ocidentais só pode derivar do que é legítimo. justo, legal e racionalmente prováve ${ }^{17}$ - ou seja, a partir de argumentos intelectuais probatórios. Os reis espanhóis teriam então o direito ao domínio imperial dos novos reinos porque declararam, de maneira justa, legítima e com boa-fé, as guerras de conquista contra os indígenas americanos.

\section{Retenção pacífica dos territórios conquistados no Novo Orbe}

Passados os primeiros tempos da conquista militar e juridica (guerra justa) reivindicada pela coroa espanhola contra os caciques indígenas do novo mundo (século XVI); o conselheiro J. Solórzano Pereira, no seu III Livro do Indiarum lure, dedicado ao governo das Índias, avançará nas exposições dos seus argumentos: jurídicos, políticos, religiosos, e econômicos; visando precisar com maior clareza a natureza legítima e legal da retenção pacífica dos territórios indígenas incorporados gradativamente à jurisdição imperial da Espanha. Jurisdição imperial altamente complexa e pouco precisa naquele tempo. isto tanto pela extensão territorial não contínua das suas fronteiras físicas, como pela ampla diversidade étnica, acolhendo povos inteiros com culturas muito diferentes, mas sendo regidos a distância mediante normas gerais dos direitos das gentes e cédulas reais do governo castelhano.

Dentro do âmbito jurídico, o erudito legalista Juan de Solorzano Pereira ${ }^{18}$ é chamado em 1609

\footnotetext{
14 "[...] las ideas expuestas y abundantemente probadas por Menchaca (lib. I Controver. Illustr. cap.9, n. 19; et cap. 10, n.2), cuando enseña que una vez que se ha declarado una guerra, incluso injusta, los príncipes adquieren el dominio no sólo de los esclavos sino también de los demás bienes. Es verdad que añade seguidamente que se ha de restituir íntegramente todo lo que se haya adquirido mal (omne plene restituendum esse, si perperam acquisitum fuerit); opinión que también abrazan, al parecer, Silvestre Prierias, Cayetano, Vitoria, Soto, Valencia y el Maestro Lorca. Todos estos sostienen que cuando una guerra ha sido injusta de suyo, pero accidentalmente justa por razón e ignorancia invencible (per accidens autem iustum ob invincibilem ignorantiam), al conocerse después la verdad sólo habrá que restituir los bienes que quedan todavía a salvo (tunc postea cognita veritate ea solum restituenda erunt quae supersunt adhuc salva aut in quibus sit factus quis ditior); pero no aquellos que de buena fe se han destruido o consumido (quae bona fide destructa aut consumpta sunt)". SOLÓRZANO PEREIRA, J. De Indiarum iure (Liber III: De Retentione Indiarum -Caput II). Madrid: Editora CSIC (Colección Corpus Hispanorum de PACE), 1994, p. 271.

15 Sobre o tratamento deliberativo dos Conselheiros do Rei e a consciência segura da decisão final política por parte do monarca, veja-se o subtítulo 1 deste trabalho.

16 SOLÓRZANO PEREIRA, J. De Indiarum iure (Liber II: De Acquisitione Indiarum - Caput VI). Madrid: Editora CSIC (Colección Corpus Hispanorum de PACE), 1999, p. 196.

17 "Toda esta doctrina está en íntima conexión con la cuestión que aquí estamos tratando: que nuestros Reyes pueden retener con justicia y seguridad los territorios que conquistaron y adquirieron, prévias esas consultas, aunque a posteriori pudiese quizá ponerse en duda la legalidad y la legitimidad de dichas consultas. En efecto, cuando un príncipe hace algo con el asesoramiento de sus nobles letrados, se presume que todo se ha llevado a cabo legitimamente y por justos motivos, de tal manera que después ya no se pueda impugnar ni poner en duda, porque lo impide la naturaleza de la sentencia y cosa juzgada (sententiae et rei iudicatae) que nace de tales consultas, criterios y diligencias". SOLÓRZANO PEREIRA, J. De Indiarum iure (Liber III: De Retentione Indiarum - Caput VI). Madrid: Editora CSIC (Colección Corpus Hispanorum de PACE), 1994, p. 269.

18 Professor na Universidade de Salamanca nas catedras: Prima de leyes (1602); Códigos (1605); Digesto Viejo (1605): Visperas de Leyes (1607). Sobre os detalhes biográficos de J. Solórzano Pereira, veja-se o interessante estudo de SÁNCHEZ MAíLLO. Carmen. El pensamiento jurídico-político de Juan de Solórzano Pereira. Navarra: Editora EUNSA, 2010, p. 53
} 
pela Coroa ${ }^{19}$ espanhola para que preste serviços como fiscal e, também, ouvidor na Real Audiencia de Charcas; instituição pública encarregada de solucionar atritos de direito no território colonial do Vicereinado do Perú. Fruto da sua experiencia profissional e familiar ${ }^{20}$ nos andes centrais latinoamericanos, Solórzano Pereira adquiriu profunda consciência das dificuldades técnicas para resolver os assuntos jurídico-políticos que atingiam diretamente a realidade viva das índias, pelo qual ele põe em consideração a publicação de um monumental texto latino ao Conde Duque de Olivares $^{21}$, valido ${ }^{22}$ do rei Felipe IV, com a elaboração e sistematização de um direito especializado para administrar de forma justa, pacifica e prudente. aquelas terras tão distantes da complacência do rei e imensamente ricas, que precisavam de um ordenamento filosófico-jurídico, do Indiarum lure, para se constituir o Direito Indiano.

A estrutura da obra, Indiarum lure, é a de um corpo sistemático e erudito no qual se encontram compiladas cédulas reais, leis, disposições ou mandatos régios; os quais eram destinados a guiar os assuntos próprios de governo nas Índias ocidentais. Da mesma maneira, o Indiarum lure é um sólido texto de filosofia prática com expressividade barroca; nele se apresenta com agudeza intelectual diversas perspectivas do direito, muitas delas contraditórias entre si, mas todas elas desdobradas em argumentos e provas possiveis de serem ditas racionalmente e serem aplicáveis juridicamente em modalidades combinadas ou mistas, dependendo do contexto social-étnico nos diversos territórios indigenas do Império espanhol.

Os reis-imperadores espanhóis dos séculos XVI-XVII (Carlos V. Felipe II, Felipe III, Felipe IV) eram figuras públicas, culturalmente refinadas e militarmente poderosas, e foram retratadas "moral e politicamente" por Solórzano Pereira nos seus Emblematas Centum Regio Politica. ${ }^{23}$ Nesta particular obra de filosofia prática, e que foi a última publicada ${ }^{24}$ pelo Conselheiro de Castilha e de Índias, o autor se mostrou como um genuíno Conselheiro de Principes, um erudito e experiente servidor da monarquia espanhola, que se atreveu a sugerir mediante lemas, imagens, epigrafes e extensos comentários, a formação especial que precisava o futuro rei, o jovem príncipe Balthasar Carlos ${ }^{25}$; outorgando conselhos precisos a seu mentor, o monarca

9 Luciano Pereña no seu estudo preliminar à edição espanhola do Indiarum lure, conta os pormenores da chegada em Perú de J. Solórzano Pereira. Em 1609 D. Pedro de Castro, Presidente do Conselho de Indias, envía ao professor de Salmanca, Juan de Solórzano Pereira, para trabalhar como ouvidor no reino do Perú. No discurso informativo à S.M. Rei Felipe IV (Doc. N 21, vol. 221), Solórzano Pereira escreveu rememorando as atividades que realizava naquele tempo: "[...] de que yo fuese a hacerme capaz de las materias de aquel Nuevo Orbe. especialmente de las tocantes a justicia y gobierno y recopilación de sus Cédulas y Ordenanzas, porque se sabía que mis letras y pluma las daría el punto de claridad que se deseaba y procurava, a imitación de las noticias, relaciones y descripciones que en tiempos antiguos solian pedir los emperadores romanos, de las provincias, aún no tan remotas, que llegaron a tener debajo de su dominio". Veja-se, PEREÑA, Luciano. Defensor oficial de la corona. In: SOLÓRZANO PEREIRA, J. De Indiarum lure (Liber III: De retentione Indiarum): Estudios preliminares. Madrid: CSIC (Colección Corpus Hispanorum de PACE), 1994, p. 21.

$20 \mathrm{~J}$. Solórzano Pereira se casa com a criolla nascida em Charcas, dona Clara Paniagua de Loaysa y Trexo. No tempo que trabalhou como ouvidor, ele influenciou com suas ideias para emendar a legislação indiana, que não estabelecia claramente a possibilidade de casamentos de espanhóis com criollas e indígenas. Motivo pelo qual casamentos interétnicos começaram a serem permitidos mais livremente no Vicereino do Perú, através da influência juridica e profissional de Solórzano Pereira. No seu livro mais difundido em lingua castelhana, Politica Indiana c. IX, p. 824, manifestou o seguinte: "[...] en estos últimos años se han concedido fácilmente algunas licencias para estos casamientos de oidores de Indias". No se puede desconocer que los criollos hacendados, además de su participación directa y oficial en el poder, muchas veces establecián conexiones familiares a través de funcionarios de todos los niveles - desde el muy alto oidor, hasta los grados inferiores- que contraían matrimonio en el distrito donde ejercian su autoridad o casaban a sus hijos com muchachas de la sociedad local. Sobre a biobibliografia do citado ouvidor, veja-se o trabalho instigante de SÁNCHEZ MAíLLO, Carmen. EI pensamiento jurídico-político de Juan de Solórzano Pereira Navarra: Editora EUNSA, 2010, p. 53.

21 O Indiarum lure (1629) foi dedicado ao Rei Felipe IV e ao presidente do governo, Conde Duque de Olivares (Dom Gaspar de Guzmán). 22 Valido ou Preferido do Rei. O beneficiário se torna por um mandato expresso do monarca em chefe administrativo do poder executivo. Ele é a mão ativa do rei que administra de forma semelhante a um primeiro ministro moderno os "assuntos de governo", razão pelo qual o valido decide o que vai ser feito ordinariamente nas questões políticas.

23 Especialmente nos Emblematas Centum Regio política (24 a 43), se trata a educação do príncipe no exercício cotidiano da virtude política. Um estudo pioneiro comparativo que enriquece a discussão erudita do século XVII sobre a educação virtuosa dos príncipes espanhóis para governar com prudência as indias ocidentais, o encontramos na obra que compara as atividades consultivas dos conseLheiros reais, Juan Solórzano Pereira e de Juan Luis López (I Marqués del Risco), escrita por BARRERO GARCIA, Ana María. El último servicio de um servidor de la corona: Los Emblematas Centum Regio Política de Solórzano Pereira", e que aparece no livro coordenado por GONZÁLEZ, Miguel Ángel. Un jurista Aragonés, el Dr. Juan Luis López, primer Marqués del Risco (1644-1703). España: Editorial de la Vicepresidencia del Gobierno de Aragón, 2007, p. 87.

24 Os Emblematas Centum Regio Política foram publicados em latim no ano de 1653. Dois anos antes do óbito de J. Solórzano Pereir em 1655. A primeira edição em latim está disponivel em: http://dadun.unav.edu/handle/10171/6259. Acesso em: 18 dez. 2019. 25 Príncipe Balthasar Carlos (1629-1646) não chegaria assumir a coroa nem conhecer os Emblematas Centum Regio Politica, redigidos por nosso autor. 
Felipe IV, de que todo soberano deve tomar sempre as decisões públicas em última instância, julgando calmamente e de forma virtuosa, aquilo que tem de ser feito no momento político certo. ${ }^{26}$ O momento da decisão final tem de seguir sempre os caminhos internos dos ensinamentos morais, jurídico-políticos e religiosos, que o monarca conservou ao longo da sua vida, recebendo as graças das divindades, atendendo as opiniões mais prováveis dos seus conselheiros, guardando os ensinamentos apreendidos da sua tradição familiar, e decidindo por si de maneira virtuosa:

Emblemata 34: "La virtud propia es muy alabada en los reyes" (Propia Virtus In Regibus

\section{Commendatio):}

Pallas me ofrece escudo de diamante,

Arco, y flechas Apolo rutilante

De Mercurio la espada

En mi lado se ha visto colocada

Pero yo, que a mi honor

Siempre me atengo,

La clave selo para mi

Prevengo:

Que aquellos dones aunque

Son vanos

No equivalen al lustre

Que mis manos

Me adquieren; porque el

Rey esclarecido
Nunca el aplauso logra,

Tan luzido

Siendo de sus mayores

Heredado

Como el que su valor le

ha conquistado. ${ }^{27}$

A virtude de um rei são suas façanhas e conquistas feitas com suas próprias mãos. O seu fazer tem de ser justo e reto, e não deve surgir do exterior outorgado de maneira pronta por outros agentes, sejam deuses ou homens. Ao contrário, o fazer do soberano tem de surgir da sua mente esclarecida, uma "secura conscientia"28, capaz de honrar com seu agir adequado as conquistas dos seus ancestrais, especialmente nas situações mais dificeis para poder reter seu reino.

Dos deuses gregos: Pallas Athena (escudo de diamante), Apolo (arco e flechas) e Mercúrio (espada), recebe como presentes um soberano para bem governar; porém os atos virtuosos que ele produza serão os forjados com suas próprias mãos ${ }^{29}$. Isto se deve a que as melhores armas para governar com retidão e justiça, se produzem de atividades honrosas que um bom soberano deve efetuar. Solórzano acredita que uma mente educada e esclarecida em assuntos públicos deve ser a que tome as decisões no mundo sensivel da república. Contudo, nosso autor aconselha os príncipes, que antes de decidir sempre escute e

\footnotetext{
26 Nos Emblematas Centum Regio Politica, J. Solórzano Pereira utiliza a linguagem metafórica da poesia barroca para comentar quando o principe deve ceder ao tempo (Tempori Cede - Emblemata XLIII) para tomar no momento politico certo suas decisões: "I... mirar al tiempo en que se negocia, sin ánimo de contrastar los huracanes del viento contrario, se ha de sufrir con paciencia aquello que no puede evitarse y aún en la fortuna deshecha, se ha de conservar la buena esperanza y rectos deseos [...] ajustar congruentemente todas sus acciones al tiempo y lugar, mitigando la severidad con el cortejo, la tristeza con la alegria, admitiendo las prosperidades y desdichas con la igualdad de un ánimo invencible, llevando con paciencia lo que el tiempo no permite evitar, y disimulando cuando no es posible la venganza ni el castigo entretejido [...] para mostrar que el sufrir y el ceder prudentemente acostumbra dar la victoria; pinta un roble robusto, que como quiere resistir la fuerza de los vientos, le arrancan y derriban: y por lo contrario, la caña siendo frágil se dobla y sujeta, con que queda intacta [...]". SOLÓRZANO PEREIRA, J. Emblematas Centum Regio Politica (Emblemata XLIII) [vol. 5, p. 82, 85, 88]. Primeira edição em lingua castelhana, Valencia, 1658. Tradução de Lorenço Matheu Sanz. Disponivel digitalmente na Biblioteca nacional de España: http://bdh-rd.bne.es/viewer.vm?id=0000144477\&page=1. Acesso em: 18 dez. 2019

${ }_{27}$ SOlÓRZANO PEREIRA, J. Emblematas Centum Regio Política (Emblemata XXXIV) Ivol. 4. p. 100-101]. Primeira edição em lingua castelhana, Valencia, 1658. Tradução de Lorenço Matheu Sanz. Disponivel digitalmente na Biblioteca nacional de España: http://bdh-rd. bne.es/viewer.vm?id=0000144477\&page=1. Acesso em: 18 dez. 2019.

${ }_{28} \quad$ "Pues bien, la mencionada retención de este Nuevo Mundo, de la que ahora tratamos, resulta también tanto más justa y segura (etiam iustior et securior efficitur) cuanto que es de todos bien sabido cómo los Reyes Católicos Fernando e Isabel y después su heredero Carlos V. Emperador Óptimo Máximo, cuando se decidieron a emprender y llevar adelante su descubrimiento y conquista, consultaron también a las personas más entendidas de aquella época sobre la justicia de esta empresa y no omitieron absolutamente nada de lo que parecia necesario para que un asunto de tanta importancia discurriera por causes de buena fe y se apoyara en una conciencia segura (ut res tanta bona fide procederet et secura conscientia) sin el menor peligro, como se ve por los documentos y dan fe de ello Pedro Malferit, el maestro Vitoria, Antonio Herrera y el muy erudito consejero Don Gregorio López Madera". SOLÓRZANO PEREIRA, J. De Indiarum iure (Liber III: De Retentione Indiarum - Caput II). Madrid: Editora CSIC (Colección Corpus Hispanorum de PACE), 1994, p. 253.

29 SOLÓRZANO PEREIRA, J. Emblematas Centum Regio Politica (Emblemata XXXIV) Ivol. 4, p. 112]. Primeira edição em lingua casteLhana, Valencia, 1658. Tradução de Lorenço Matheu Sanz. Disponivel digitalmente na Biblioteca nacional de España: http://bdh-rd.bne. es/viewer.vm?id=0000144477\&page=1. Acesso em: 18 dez. 2019.
} 
avalie cuidadosamente as opiniões prováveis dos seus Conselheiros: Reais, das Juntas dos reinos (assembleias), das Índias (para assuntos referidos a esses territórios), administradores políticos (Virrey, Governadores, Corregedores, e finalmente os conselhos dos Caciques indígenas). Estes últimos, foram úteis especialmente em temas de tributos e trabalhos forçados, os quais eram ditos de utilidade pública para as colônias americanas.

O sistema de governo monarquista espanhol estava assentado numa forte tradição de Conselhos reais ${ }^{30}$, integrados por homens aristocratas que conformavam o estamento da nobreza hispânica. Era um conclave que utilizava distintos critérios racionais, oferecendo possiveis soluções aos conflitos do império. O rei devia ver, escutar, avaliar e depois decidir as medidas a serem tomadas. Segundo Solorzano, isso acontecia nas deliberações tomadas nas indias ocidentais:

[2-3] En verdad los muy cristianos y poderosos Reyes de nuestra España tuvieron siempre por costumbre emprender y realizar todas las cosas, sobre todo las importantes y arduas, con el asesoramiento de los peritos, y ajustar su voluntad a la razón y a la normatividad legal [...]. [19] Acertadamente enseña Salustio que nunca se han de declarar y emprender guerras sin una detenida y madura consulta y deliberación (et matura consultatio et deliberatio desideretur), y que los motivos y la justicia de ella se han de examinar por personas muy competentes: Antes de empezar, consulta; y una vez que hayas deliberado maduramente, es preciso actuar. [...]. [24-26] Todos estos factores han estado ampliamente presentes en el descubrimiento y conquista del Nuevo Mundo que estamos considerando, puesto que nuestros Reyes no solamente han consultado a las personas más competentes y doctas de sus reinos, sino incluso a la misma Sede Apostólica (cum reges nostri non solum prudentissimos et eruditissimos regnorum suorum viros consuluerint. sed etiam ipsam Apostolicam Sedem). de acuerdo com lo que se ordenaba em el antiguo testamento (Dt 17 [8-11]): Si una causa te parece demasiado dificil de sentenciar, causas dudosas de homicidio, pleitos, lesiones, que surjan en tus ciudades, acudirás a los sacerdotes levitas, al juez que esté en funciones y les consultarás; ellos dictarán sentencia". ${ }^{11}$

Os conselhos abriram pacificamente a forma pura de governo monárquico para a configuração de um sistema original e misto de governo com processos deliberativos e de estabilidade local; onde distintas instâncias aristocráticas cooperavam ativamente na geração de governança, promovendo conhecimentos prováveis de situações e de experiências concretas, para que assim o Rei tenha mais informações concebiveis e tome suas decisões finais da forma mais prudente possivel e efetiva:

[...] sobre el Consejo y consejeros de los principes y sobre su necesidad, utilidad. dignidad y calidad exponen Bártolo, Nicolás Bohier, Martín de Cazariis Laudense [...] Padre Juan Pineda, quién prueba que los consejeros son los ojos y los oídos de los Príncipes (ubi consiliarios oculos atque aures principum esse probat) [...]. [40-41] En efecto, cuando un príncipe hace algo con el asesoramiento de sus nobles letrados, se presume que todo se ha llevado a cabo legitimamente y por justos motivos [...] [42-44] En la misma linea se halla el Padre José de Acosta (De procur. Ind. Sal. lib.II, cap. 11; et lib. III, cap 3), quién concluye, en su elegantísimo estilo, que no conviene seguir disputando más en este asunto, sino que, como de cosa que ya ha prescrito, hay que proceder con la mejor buena fe (sed veluti praescriptum iam sit, optima fide agi debere). ${ }^{32}$

No caso das indias ocidentais, o Supremo Conselho de Índias, assessorava continuamente ao Rei sobre os estados de coisas que estavam

\footnotetext{
30 "[...] los poderosos, y Católicos Reyes, que tienen distribuidos en diferentes clases de Senados todos los negocios de su dilatado Imperio, así de guerra como de paz, de fuerte que no hay cosa grave que no se consulte y comunique primero con escogidísimos Consejeros de todos grados, según la calidad del negocio, para que conforme sus consultas puedan más fácilmente despacharlos todos. [...] [44] provecho de los Consejos, y Consejeros, con los cuales no se disminuye en nada la Real dignidad, y soberania, y que esto no fuerza a los Reyes, sino solo les encamina; porque despues de haber oido y considerado lo que todos dicen, queda en su libertad para escoger. y ejecutar lo que le parece mejor [...]". SOLORZANO PEREIRA, J. Emblematas Centum Regio Política (Emblemata XLV) Ivol. 5. p. 229-230]. Primeira edição em lingua castelhana, Valencia, 1658. Tradução de Lorenço Matheu Sanz. Disponivel digitalmente na Biblioteca nacional de España: http://bdh-rd.bne.es/viewer.vm?id=0000144477\&page=1. Acesso em: 18 dez. 2019.

31 SOLÓRZANO PEREIRA, J. De Indiarum iure (Liber III: De Retentione Indiarum - Caput II). Madrid: Editora CSIC (Colección Corpus Hispanorum de PACE), 1994, p. 253, 259, 261.

32 SOLÓRZANO PEREIRA, J. De Indiarum iure (Liber III: De Retentione Indiarum - Caput II). Madrid: Editora CSIC (Colección Corpus Hispanorum de PACE), 1994, p. 255 e 269.
} 
acontecendo nesses distintos territórios. Igualmente, o monarca ponderava informes governamentais de Virreis, Governadores provinciais, Corregedores, e demais magistrados; 33 os quais lhe avisavam sobre situações de crises, rebeliões, conversões de infiéis, arrecadações etc., que aconteciam nos vice-reinados afastados do Império espanhol. Finalmente, no âmbito do Poder Executivo, a república mista ou misturada indiana tinha na sua estrutura organizacional os Caciques indigenas, que pela sua linhagem real eram integrados organicamente ao poder público da coroa, a fim de que imponham autoridade e respeito aos vassalos dos Impérios desaparecidos: Incas, Maias, Astecas etc.

Os Caciques representavam fisicamente aos antigos tiranos que governavam ancestralmente esses territórios. A coroa espanhola os utilizava na sua primeira linha de frente contra os vassalos indígenas, exercendo através do medo, da força e da linguagem imperativa, os comandos reais, para que se paguem os impostos e se realizem os serviços obrigatórios ditos de "utilidade pública" contra os homens indígenas. Diz Solórzano no Indiarum lure:

En mis apuntes privados tengo dividida la materia en cinco libros. El primero de ellos lo dedicaremos a tratar el estado y condición de los indios: si se les puede obligar y en qué medida a las cargas y servicios que se ven forzados a soportar por turnos sirviendo a los españoles en los edificios públicos, en el cultivo de los campos, en el apacentamiento y guarda de los rebaños de ovejas y bueyes, en los talleres de mujeres tanto de tejidos como de lanas (lo que vulgarmente se llaman obrajes), en los correos y mensajeros por los caminos públicos, en lo caballos de posta y de viaje, en los metales y su extracción y manufacturación. Que tributos están obligados a pagar y como se han de dividir, tasar y exigir. Finalmente lo mucho que importa reunirlos en determinados municipios y bajo una forma civilizada y sociable de vida; remediar la idolatria, la embriaguez y demás vicios que tienen. proveerles de buenos gobernantes, vulgarmente llamados curacas y caciques. Que poder tienen éstos y su modo de sucesión. Que privilegios disfrutan los indios, como incultos que son y personas menores de edad y miserables en todos los aspectos. ${ }^{34}$

Dominados violentamente pelos Caciques e Curacas, ${ }^{35}$ os homens indigenas (de 18 a 50 anos) estavam obrigados de realizar trabalhos forçados e pagar tributos para a coroa espanhola. Esses trabalhos forçados eram chamados de utilidade pública e consistiam em trabalhos na construção de prédios públicos, estradas e igrejas; cultivos de alimentos básicos; tecidos (obrajes); mineria tanto em extração como em manufatura (mita mineira). Trabalhos que exigiam um esforço desmedido, físico e mental, que terminava liquidando a vida da maioria dos indigenas.

Os governadores locais defendiam os trabalhos de utilidade pública, afirmando que seguiam e cumpriam com as disposições reais, beneficiavam o erário público da monarquia de forma significativa e, finalmente, porque os indigenas aceitavam esses trabalhos de forma voluntaria para obter algum dinheiro para sobreviver. Somado a esses abusivos trabalhos públicos, os espanhóis e criollos forçavam cotidianamente aos indigenas para realizar trabalhos privados, chamados de Yanaconazgo, nas casas e fazendas espanholas, o qual retirava a dignidade moral e a saúde dos indígenas, já que nesta forma de emprego se tornavam servos de amos abusivos:

Hoy día se encuentran los indios en condiciones más duras y peor tratados por gente injusta y cruel que en otro tiempo los judíos, cuando estuvieron cautivos en Egipto. De ellos dijo Filón: Cautivos como por derecho de guerra. comprados en almoneda, los obligaban a trabajos serviles. [...] Pero los indios casi en el mismo plazo de tiempo han sido arrasados y exterminados en su mayor parte, de suerte que puede decir

33 "El libro cuarto tratará sobre el gobierno civil, y en especial expondrá el cometido, potestad y jurisdicción de los Presidentes, Gobernadores de Audiencias, Fiscales, Alcaldes del crimen, Oidores de Audiencias, Virreyes, Consejo Supremo de Indias y en fin de todos los magistrados de mayor o menor rango designados para desempeñar las tareas de dicho gobierno". SOLORZANO PEREIRA, J. De Indiarum iure (Liber III: De Retentione Indiarum - Caput VIII et Ultimum). Madrid: Editora CSIC (Colección Corpus Hispanorum de PACE), 1994, p. 471. 34 SOLÓRZANO PEREIRA, J. De Indiarum iure (Liber III: De Retentione Indiarum - Caput VIII et Ultimum). Madrid: Editora CSIC (Colección Corpus Hispanorum de PACE), 1994, p. 469.

35 Sobre os abusos históricos dos Caciques e outros funcionários de governo nas Índias, veja-se o estudo de GARCIA AÑOVEROS, Jesús Maria. La idea "Status" y función del indio en Juan de Solórzano Pereira.In: SOLÓRZANO PEREIRA, J.De Indiarum lure (Liber III: De retentione Indiarum): Estudios preliminares.Madrid: CSIC (Colección Corpus Hispanorum de PACE), 1994, p. 111-191. 
a Dios lo que se lee en el libro de Daniel (3 [37] refiriéndose a los judios: Señor. hemos disminuido más que todas las naciones, hoy estamos humillados en toda la tierra. ${ }^{36}$

Solórzano escreveu frontalmente contra los Yanaconzagos, desnudando os excessos cometidos por espanhóis e criollos americanos contra as vidas dos indígenas, razão pela qual será censurada uma parte da sua obra e aparecerá seu título no Index librorum prohibitorum, pelo qual ele se verá forçado a suprimir as partes mais críticas contra os trabalhos forçados, públicos e privados, nas fronteiras das colônias das indias ocidentais. O censor da Coroa, Don Joseph de Nápoles, fez um informe especial ${ }^{37}$ para o Rei, apontando as partes que deveriam ser reescritas pelo autor do Indiarum lure, para que dessa nova forma, sim possa ser publicado o livro e não apareça mais no Index librorum prohibitorum:

Mas porque movido del zelo que tiene en cassi todo el tratado viene a insinuar la grande opressión y continuas vejaciones que hazen los españoles a los Indios y quán injustamente los maltratan y la avaricia y codicia que llevan en esto; y no se puede negar que con esto desdora la nación española, y que lo affirme y repplique tantas veces un Ministro de V.Md. y del Consejo de Indias, que estubo tantos años en ella, y que habla como testigo de vista en muchas cosas, y que dará motivo y ánimo a los émulos y enemigos de esta Corona a escrivir en la misma conformidad, valiéndose de la autoridad de Don Juan Solórzano Pereira y bolviendo a resucitar los antiguos assuntos de que esta conquista toda han emando por interés y no zelo, me parece que todo esto se podrá reparar. [...] En el Cap.4. n. 37 también se podría moderar algo acerca de la oppresión con que tratan los españoles a los indios. En el Cap. 7 se haze mención de una Instrucción secreta que se enbió el año de 95 a Don Luis de Velasco, y si ésta no se publicó despúes no combiene que ande en libros estampados que llegan a las manos de todos. ${ }^{38}$

A imagem corriqueira que se difunde de Juan de Solórzano Pereira, como a de um frio e calculador pensador da razão de Estado é falsa, porque ao longo das suas obras fundamenta de forma erudita tanto os argumentos da dominação política espanhola como também reflete e questiona os abusos excessivos cometidos contra os indigenas, desnudando os problemas sociais e políticos de um regime monárquico conservador. que considerava formalmente os indigenas como homens livres e vassalos ${ }^{39}$ da coroa espanhola, contudo ao mesmo tempo tratava-lhes como escravos ou servos de última classe, sendo de fato os pés que retinham com suor e dor, todo o peso da conquista.

Finalmente, na figura solorziana de república mista, o tema da formação cultural dos vassalos indigenas nos valores cristãos se torna crucial. Por um lado, a temática da civilização ou educação ou formação ${ }^{40}$ dos indígenas para a cidadania cristã procura amadurecer o espírito humano dos novos conversos mediante a compreensão dos fundamentos "ético-religiosos" de: paz, concórdia, amor, suavidade e civilidade. Por outro lado, essa temática pecou por tratar aos indígenas como menores de idade, crianças incapazes de decidir em qualquer situação, pelo qual deviam seguir o comando de um vassalo espanhol, mesmo em qualquer processo judicial que envolvesse seus

\footnotetext{
36 SOLÓRZANO PEREIRA, J. De Indiarum iure (Liber III: De Retentione Indiarum - Caput VIII et Ultimum). Madrid: Editora CSIC (Colección Corpus Hispanorum de PACE), 1994, p. 475.

37 (Archivo General de Simancas, E, 2660, a 12 de marzo ade 1638).

38 (Archivo General de Simancas, E, 2660, a 12 de marzo ade 1638).

39 "Otras instrucciones, ordenanzas y cédulas -que recoge el mismo Herrera- dadas en años subsiguientes a diversos capitanes, conquistadores y gobernadores expresan con no menos energía ese mismo celo ardiente de predicar y propagar suave y pacíficamente entre los indios la fe y religión cristiana y la constante preocupación de nuestros Reyes por instruirlos, defenderlos y tratarlos bien. [...] una notable cédula de nuestro piadosísimo y prudentísimo Rey Felipe II en Lisboa el 27 de mayo de 1582 al arzobispo de Lima, en la que reprende severamente los daños y vejaciones inferidos a los indios y se duele amargamente de no haberse observado, como convenía lo establecido para cortar y castigar estos abusos. Dice asi: Y porque habiéndose proveido tan cumplidamente lo que ha parecido convenir al bien espiritual y temporal y conversión de los dichos indios, teniendo tanto cuidado de procurar que fuesen doctrinados e instruidos en las cosas de nuestra santa fe católica, mantenidos en justicia y amparados en su libertad como súbditos y vasallos nuestros, entendiamos que nuestros ministros cumplian lo que habiamos ordenado. Y de no haberlo hecho ni cumplido y llegado a estado de tanta miseria y trabajos, nos ha dolido, como es razón. [..... Hay también otras dos cédulas de 5 y 31 de diciembre de año de 1608 dirigidas al excelentísimo Virrey Marqués de Montesclaros [...]".SOLÓRZANO PEREIRA, J. De Indiarum iure (Liber III: De Retentione Indiarum - Caput VI). Madrid: Editora CSIC (Colección Corpus Hispanorum de PACE), 1994, p. 385, 387.

40 Ideias humanistas de Paideia grega e Bildung germânica são presentes na formação cristã dos indios.
} 
interesses, já que se lhes proibia se defender e até juramentar, indicando a falta de capacidade juridica dos indigenas. Esses preconceitos de época são também visiveis na Política Indiana de Solórzano Pereira:

Goce[n] de todos los favores y privilegios de los menores. Asegura Solórzano que "supuesto que no se puede poner en duda que los indios por las razones referidas son miserables personas, tampoco la tiene que hayan de gozar y gocen de todos los favores y privilegios que a los menores, pobres rústicos y otros tales se conceden, asi en lo judicial como en lo extrajudicial" $(I I, 28,24)$. "Por el consiguiente les compete este beneficio de la restitución in integrum: no se presume en ellos dolo ni engaño: están libres de tutela y otras cargas de este género: sus pleitos se han de determinar breve y sumariamente, sin atender las escrupulosas fórmulas del derecho $(I I, 28,25)$. [...] No se les tome juramento en causas y pleitos. Asi lo defiende Solórzano "por el peligro o riesgo en que los ponemos de que se perjure con facilidad, como personas que no hacen bastante concepto de la fuerza del juramento, ni de la obligación de decir la verdad y deponen de ordinario en la forma que los instruyen o persuaden, o en la que entienden será más del gusto del juez que los examina $(I I, 28,33) .{ }^{41}$

O tipo de servidão nas Índias ocidentais foi mais próximo da servidão medieval que da escravidão antiga. Contudo, os indígenas eram considerados como os vassalos de última categoria no reinado espanhol, pelo qual seus direitos eram extremadamente limitados, porque eles foram tutelados ao longo dos séculos XVI-XVII, considerados como inferiores intelectualmente, o qual os levou a realizar trabalhos físicos extremos para tentar sobreviver com o mínimo material possivel.

Os fundamentos da liberdade foram amplamente comprometidos no sistema de governo operante nas Índias ocidentais do século XVII, e Sólorzano Pereira reproduziu o discurso condescendente com os serviços obrigatórios, os trabalhos forçados para garantir a utilidade pública do império espanhol, apesar de minar diretamente as liberdades individuais dos vassalos, especialmente, dos vassalos indigenas. Esse preconceito pré-moderno contra a liberdade individual, impediu claramente o livre desenvolvimento do ser humano residente na América Colonial enquanto individuo capaz de poder decidir autonomamente sobre sua vida. É assim que a República espanhola do século XVII, tutelou temporal e espiritualmente todas as atividades humanas nas suas fronteiras sem permitir a seus súditos apropriar-se espontaneamente da vida política, econômica e religiosa:

En una República concertada la autoridad puede obligar a los vasallos a realizar servicios obligatorios en las cosas que son de común provecho: los servicios de utilidad pública no se pueden suprimir sin menoscabo de todo el Reino; es costumbre antigua introducida, cuya supresión acarrearía graves prejuicios a los españoles, a los mismos indigenas y pondría en peligro la conservación de las Indias; aunque resulten daños para los naturales, se trata de um mal necesario y no es mal el que se compensa con un mayor bien: éstos han recibido muchos bienes espirituales y materiales de los españoles y es justo que, de alguna manera correspondan a ellos con sus servicios; los servicios obligatorios son lícitos si hay causa justa y los pide el bien universal: están permitidos por reales cédulas. [...] Dentro de los servicios de utilidad pública, los referentes a minas y beneficios de metales eran objeto de fuerte polémica por las graves consecuencias que tenian para los indios y la decisiva importancia para la Monarquia. ${ }^{42}$

\section{Considerações finais}

Neste estudo apresentei e discuti detalhadamente as ideias político-juridicas mais prováveis sobre guerra e paz, de Juan de Solórzano Pereira. Essas ideias se encontram desdobradas em 10 princípios conclusivos:

\footnotetext{
41 GARCIA AÑOVEROS, Jesús Maria. La idea "Status" y función del indio en Juan de Solórzano Pereira. In: SOLÓRZANO PEREIRA, J. De Indiarum lure (Liber III: De retentione Indiarum): Estudios preliminares. Madrid:CSIC (Colección Corpus Hispanorum de PACE), 1994, P. 120-121. O estudo cita a versão castelhana da Politica Indiana, de Juan Solorzano Pereira.

42 GARCIA AÑOVEROS, Jesús Maria. La idea "Status" y función del indio en Juan de Solórzano Pereira. SOLÓRZANO PEREIRA, J. De Indiarum lure (Liber III: De retentione Indiarum): Estudios preliminares. Madrid:CSIC (Colección Corpus Hispanorum de PACE), 1994, p. 170-171. O estudo cita a versão castelhana da Política Indiana, de Juan Solorzano Pereira.
} 
1. Solórzano Pereira delineou de maneira erudita no Indiarum lure, aquilo que seria a guerra justa e suas situações prováveis de legitimidade e legalidade. levando em cada caso fundamentações racionais possiveis, a fim de fazerem-se compreender, quando e por que se tornaria importante para um Estado intervir militarmente em um conflito armado, o qual não apresenta nenhuma forma possivel de resolução pacífica;

2. Solórzano Pereira interpretou as tradições filosófico-jurídicas e religioso-cristãs, para intentar averiguar o valor real do justo título: "Domínio Imperial das Índias Ocidentais", mediante usos racionais de opiniões prováveis perante dúvidas de se houve ou não houve alguma situação de guerra justa dos espanhóis contra os indigenas do Novo Mundo;

3. o que considera Solórzano a opinião mais provável? A opinião mais provável seria a opinião que se aproxima racionalmente daquilo que pode ser a verdade na realidade, na medida em que essa opinião argumenta claramente desvelando os problemas contidos nas dúvidas de fato e de direito, apresentadas nas outras opiniões prováveis. Contudo, a opinião mais provável expressa a forma mais segura possivel para resolver os conflitos "interpretativos e compreensivos" da verdade daquele assunto na realidade;

4. na visão de Solórzano Pereira, a opinião mais provável tem o sustento material no ato perfeito presente no império da lei, e tem o sustento formal expresso nos fundamentos e princípios do direito natural, civil e das gentes. A opinião mais provável tem validade no ato presente da realidade reconhecido nos princípios próprios do direito, como são: boa-fé, aquisição, usucapião, retenção, prescrição, restituição etc.

5. Na Filosofia do Direito Indiano de Solórzano Pereira, a opinião provável não necessariamente se restringe aos atos perfeitos e absolutos que se acreditam ter em opiniões mais prováveis do passado e do presente, porque a probabilidade nessa filosofia está aberta ao futuro condicional, onde novas opiniões podem produzir dúvidas nos fatos e no direito, podendo-se tornar em opiniões mais coerentes, seguras e mais prováveis que as anteriores, pela aceitabilidade racional sobre o direito em questão. Erros abrem brechas e podem ser motivos suficientes para modificar direitos por usucapião, retenção, prescrição, restituição etc.

6. a estrutura da obra, Indiarum lure, é a de um corpo sistemático e erudito no qual se encontram compiladas cédulas reais, leis, disposições ou mandatos régios; os quais eram destinados a guiar pacificamente os assuntos próprios de governo nas Índias ocidentais. Da mesma maneira, o Indiarum lure é um sólido texto de filosofia prática com expressividade barroca; nele se apresenta com agudeza intelectual diversas perspectivas do direito, muitas delas contraditórias entre si, mas todas elas desdobradas em argumentos e provas possiveis de serem ditas racionalmente e serem aplicáveis juridicamente em modalidades combinadas ou mistas, dependendo do contexto social-étnico vivido nos diversos territórios indigenas do Império espanhol;

7. o sistema de governo monarquista espanhol estava assentado, segundo o Indiarum lure, em uma forte tradição de Conselhos reais, integrados por homens aristocratas que conformavam o estamento da nobreza hispânica. Era um conclave que utilizava distintos critérios racionais, oferecendo possiveis soluções aos conflitos do império. O rei devia ver, escutar, avaliar, e depois decidir as medidas a serem tomadas. Segundo Solorzano, isso acontecia nas deliberações tomadas nas diferentes jurisdições da Indias ocidentais:

8. os Conselhos abriram pacificamente a forma pura de governo monárquico para a configuração de um sistema original e misto de governo com processos deliberativos e de estabilidade local; onde distintas instâncias aristocráticas cooperavam ativamente na geração de 
governança, promovendo conhecimentos prováveis de situações e de experiências concretas, para que assim o Rei tenha mais informações concebiveis, e tome suas decisões finais da forma mais prudente possivel e efetiva;

9. especificamente no caso das Índias ocidentais, o Supremo Conselho de índias, assessorava continuamente ao Rei sobre os estados de coisas que estavam acontecendo nesses distintos territórios. Igualmente, o monarca ponderava informes governamentais de Virreis, Governadores provinciais, Corregedores, e demais magistrados; os quais the avisavam sobre situações de crises, rebeliões, conversões de infiéis, arrecadações etc., que aconteciam nos vice-reinados afastados do Império espanhol. Finalmente, no âmbito do Poder Executivo, a república mista ou misturada indiana tinha na sua estrutura organizacional aos Caciques indigenas, que pela sua linhagem real eram integrados organicamente ao poder público da coroa, a fim de que imponham autoridade e respeito aos vassalos dos Impérios desaparecidos: Incas, Maias, Astecas etc

10. a imagem corriqueira que se difunde de Juan de Solórzano Pereira, como a de um frio e calculador pensador da razão de Estado, considero que é falsa, porque ao longo das suas obras Solórzano fundamenta de forma erudita tanto os argumentos da dominação política espanhola como também reflete e questiona os abusos excessivos cometidos contra os indigenas. Desnudando os problemas sociais e políticos de um regime monárquico conservador, que considerava formalmente aos indígenas como homens livres e vassalos da coroa espanhola, porém, ao mesmo tempo tratava-lhes como escravos ou servos de última classe, sendo de fato os pés que retinham com suor e dor, todo o peso da conquista espanhola.

\section{Referências}

ACOSTA, José de. Historia natural y moral de las Indias en que se tratan las cosas notables del cielo y elementos, metales, plantas, y animales dellas y los ritos, y ceremonias, leyes y gobierno, y guerras de los indios. Impresso em Sevilla, Juan de Leon 1590.Versão disponivel em: http://www.memoriachilena.cl/602/w3-article-8652.html e http://www. iberoamericadigital.net/BDPI/. Acesso em: $18 \mathrm{dez}$. 2019. https://doi.org/10.5962/bhl.title.137953

AZANZA, José Javier; ZAFRA, Rafael. Deleitando enseña. Una lección de emblemática. Pamplona: Universidad de Navarra, 2009.

BACIERO, Carlos. Fundamentación filosófica de la defensa de la corona ante Europa. In: SOLÓRZANO PEREIRA, J. De Indiarum lure (Liber III: De retentione Indiarum): Estúdios preliminares. Madrid: CSIC (Colección Corpus Hispanorum de PACE), 1994.

BARNADAS, J. M. Bibliotheca Boliuiana Antiqua Impresos coloniales (1534-1825), 2vols. Sucre: Fundación Cultural del Banco Central de Bolivia / Archivo y Biblioteca Nacionales de Bolivia / Centro Boliviano de Estudios Avanzados, 2008.

BARNADAS, J. M. Catálogos bibliográficos: Fondo antiguo del Archivo y Biblioteca Nacionales de Bolivia; Fondo antiguo del Archivo - Biblioteca Arquidiocesanos Monseñor Taborga. Sucre - Bolivia: Fundación MAPFRE TAVERA, 2003. (CD)

BARRERO GARCÍA, Ana María. El último servicio de um servidor de la corona: Los Emblematas Centum Regio Política de Solórzano Pereira. In: GONZÁLEZ Miguel Ángel (coord.). Un jurista Aragonés, el Dr. Juan Luis López, primer Marqués del Risco (16441703). España: Editorial de la Vicepresidencia del Gobierno de Aragón, 2007.

CULLETON, Alfredo; HOFMEISTER PICH, Roberto (ed.). Right and Nature in the first and second Scholasticism. Belgium: Publishing by Brepols, 2014.

GARCIA AÑOVEROS, Jesús Maria. La idea "Status" y función del indio en Juan de Solórzano Pereira. In: SOLÓRZANO PEREIRA, J. De Indiarum lure (Liber III: De retentione Indiarum): Estudios preliminares. Madrid: CSIC, 1994. (Colección Corpus Hispanorum de PACE)

HOFMEISTER PICH, Roberto. Revisiting the Topic of the «Law of War »: The Comments on Thomas Aquinas' Summa theologicae Ilallae 9.40 aa.1-4 by Fernando Pérez (16th Century). In: CULLETON, A.; HOFMEISTER PICH, R. (ed.). Right and Nature and the First and Second Scholasticism. Belgium: Brepol 2014.

LÓPEZ POZA, Sagrario. Los libros de emblemas como "tesoros" de erudición auxiliares de la "inventio. In: ZAFRA, R.; AZANZA, J.J. Emblemata aurea. La emblemática en el arte y la literatura del siglo de oro. Madrid: Akal, 2000.

PEREÑA, Luciano. Defensor oficial de la corona. In: SOLÓRZANO PEREIRA, J. De Indiarum lure (Liber III: De retentione Indiarum): Estudios preliminares. Madrid: CSIC, 1994. (Colección Corpus Hispanorum de PACE) 
PONCELA GONZÁLEZ, Ángel. Filosofía del Derecho en sentido pragmático: Francisco de Vitoria y la escuela de Salamanca. In: CULLETON, A.; HOFMEISTER

$\mathrm{PICH}, \mathrm{R}$. (ed.). Right and Nature and the First and Second Scholasticism. Belgium: Brepol, 2014. https://doi.org/10.1484/M.RPM-EB.5.103148

SÁNCHEZ MAÍLLO, Carmen. El pensamiento jurídico-político de Juan de Solórzano Pereira. Navarra: Editora EUNSA, 2010

SOLÓRZANO PEREIRA, J. De Indiarum iure (Liber II: De Acquisitione Indiarum). Madrid: Editora CSIC, 1999. (Colección Corpus Hispanorum de PACE)

SOLÓRZANO PEREIRA, J. De Indiarum iure (Liber III: De Retentione Indiarum). Madrid: Editora CSIC, 1994. (Colección Corpus Hispanorum de PACE)

SOLÓRZANO PEREIRA, J. Emblematas Centum Regio Política. Primeira edição em língua castelhana, Valencia, 1658. Tradução de Lorenço Matheu Sanz. Disponivel em: http://bdh-rd.bne.es/viewer.vm?i$\underline{d=0000144477 \& \text { page }=1}$. Acesso em: 18 dez. 2019.

\section{SUÁREZ, Francisco. De Legibus (Caput IV, De iure} gentium). Madrid: C.S.I.C., 1973

TINAJEROS, Gonzalo. Um estudo filosófico comparado sobre o conceito de Guerra Justa em F. Vitoria, J. Solórzano Pereira e G.W.F. Hegel. Revista Clássica Boliviana, n. IX, Sociedad Boliviana de Estudios Clásicos (SOBEC). La Paz: Marigalante, 2018. pp. 121-152. Disponivel em: http://www.estudiosclasicosbolivia.org//MG/pdf/ classica_ix_colores.pdf. Acesso em: 18 dez. 2019.

TOSI, Giuseppe. Sins Against Nature as Reasons For a "Just War": Sepúlveda,

Vitoria and Las Casas. In: CULLETON, Alfredo; HOFMEISTER PICH, Roberto (ed.). Right an Nature in the firstand second Scholasticism. Belgium: Turnhout, Publishing by Brepols, 2014.

VITORIA, Francisco de. De indis, siue de iure belli hispanorum in barbaros.

Edited by James Brown Scott (A photographic reproduction of Simon's edition of 1696). Washington: Carnegie Institution, 1917.

VITORIA, Francisco de. Relección I de los Indios recientemente descubiertos. México: Editorial Porrúa, edición de Antonio Gómez Robledo, 2007.

\section{Gonzalo Tinajeros Arce}

Doutor em Filosofia pela Universidade Federal do Rio Grande do Sul (UFRGS, Porto Alegre, RS, Brasil), pós-doutorando em Filosofia escolástica do período colonial latino-americano na Pontifícia Universidade do Rio Grande do Sul (PUCRS, Porto Alegre, RS, Brasil).

\section{Endereço para correspondência}

Gonzalo Tinajeros Arce

Pontifícia Universidade Católica do Rio Grande do Sul

Av. Ipiranga, 6.681, Prédio $8,4^{\circ}$ andar, sala 403

Partenon, 90619900

Porto Alegre, RS, Brasil 